\title{
Preparation of Cu-BTC Supported Fly Ash-Based Catalyst and Research on Low-Temperature SCR Denitration Performance
}

\author{
Yuling Liu ( $\sim$ lyl29992359@163.com ) \\ Xi'an university of technology \\ Shu Hao \\ Xi'an University of Technology
}

\section{Research Article}

Keywords: Cu-BTC/FA, Denitration and sulfur resistance, Fly ash, Selective catalytic reduction, Solid waste resource utilization

Posted Date: October 25th, 2021

DOI: https://doi.org/10.21203/rs.3.rs-992893/v1

License: (c) (1) This work is licensed under a Creative Commons Attribution 4.0 International License.

Read Full License 


\section{Abstract}

The novel Cu-BTC/FA materials were synthesized with Cu-BTC as the active component and solid fly ash as the catalyst carrier. then developed as the NO removing catalysts for low temperature selective catalytic reduction (SCR) with $\mathrm{NH}_{3}$. The physic-chemical properties of catalyst samples were characterized by multiple techniques, such as SEM, XRD, FTIR, XPS, TPR and Raman. The results show that: (1) The active component Cu-BTC loading ratio is $9 \%$, the denitration performance is excellent and has strong stability. Under this condition, the catalyst showed the highest $\mathrm{NH}_{3}-\mathrm{SCR}$ activity, giving $94 \%$ NO conversion. (2) The catalysts show the good cyclic and stability in SCR denitration under $200{ }^{\circ} \mathrm{C}$. (3) It still shows high $\mathrm{NO}$ removal rate and good stability under the condition of $\mathrm{SO}_{2}$, and the denitration rate is as high as $78.36 \%$. (4) There is a certain degree of resource integration for carrier fly ash, which not only treats air pollutants to a certain extent, but also achieves the purpose of solid waste recycling.

\section{Highlights}

-Cu-BTC can be used as an excellent carrier in denitration.

- the main metal active species is $\mathrm{Cu}^{2}+/ \mathrm{Cu}^{+}$.

-The denitration rate is as high as $94 \%$.

-Under $\mathrm{SO}_{2}$, shows a high NO removal rate and good stability.

\section{Introduction}

The waste gas pollution of coal chemical enterprises has the characteristics of a wide range of emissions, a large amount of emissions, and the waste gas often contains toxic and harmful substances, which form a certain obstacle to the overall development of the social economy [1-3]. At the same time, it has a great negative impact on the living environment of mankind. The crude coal gas produced by the coking furnace passes through the condenser and the raw gas produced enters the gas boiler [4]. The main pollutants produced are sulfur dioxide $\left(\mathrm{SO}_{2}\right)$, nitrogen oxides $\left(\mathrm{NO}_{\mathrm{x}}\right)$ [5]. The discharge of these pollutants into the atmosphere has caused serious environmental problems. Therefore, the treatment of NOx is imminent [6-7].

At present, the most widely used NOx removal technology is selective catalytic reduction method in which the reducing agent selectively reacts with the NOx in the flue gas in the presence of a catalyst, and finally reduces the NOx to harmless $\mathrm{N}_{2}$ and $\mathrm{H}_{2} \mathrm{O}$ [8-9]. The reaction temperature of this method is low, generally not higher than $400^{\circ} \mathrm{C}$ [10]. It is currently recognized at home and abroad with a wide range of applications and better denitration performance [11].

As a key factor for SCR denitration, catalyst is also an important reason for the success or failure of the st with good performance not only has strong 
stability, high NO conversion rate and wide temperature window, but also has good sulfur and water resistance [12-13]. According to the different active components of the catalyst, the catalyst is divided into noble metals catalysts, molecular sieve catalysts, metal oxide catalysts. Noble metals have good stability and good low-temperature catalytic activity, and high denitration efficiency [14].

At present, the more mature catalysts for industrial applications are mainly the mixture of vanadiumtitanium base and molybdenum trioxide or tungsten trioxide [15]. This catalyst is mainly active in the temperature range of $380-450^{\circ} \mathrm{C}$, and its pores will be formed by side reactions when the temperature is lower than $420^{\circ} \mathrm{C}[16-18]$. The blockage of ammonium sulfate causes a decrease in catalytic activity, and it is easy to leak vanadium-containing compounds into the atmosphere at high temperatures, which reduces the denitrification performance and also causes secondary pollution to the environment [19-20]. Therefore, it is imperative to develop a catalyst with good low temperature effect and high NO removal rate.

Metal-organic framework (MOFs) materials are a kind of open crystal framework materials with adjustable pore size and permanent porous structure that are assembled by metal-containing units and organic ligands under certain conditions [21-22]. Because of its ultra-high specific surface area, strong adsorption capacity, multifunctional metal center and modifiable pores, it is widely used in many fields [23-24]. Among them, in the catalytic process, on the one hand, the high specific surface of the MOFs material is conducive to the adsorption and enrichment of the substrate molecules around the active center. On the other hand, the structural properties of inorganic-organic hybrid MOFs provide the possibility to form one or more catalytic centers in a single pore. Therefore, MOFs are a new type of solid catalytic material with broad application prospects [25].

There are certain researches on the application of metal-organic framework to SCR denitration. At present, the prepared MOFs are compressed for denitration and have a good treatment effect, but the preparation time is too long, the preparation amount is small, and the cost is too high. Therefore, the bottleneck encountered at present is how to industrialize it.

As a kind of solid waste with relatively large output, fly ash needs to be resolved in a reasonable manner. Fly ash is a special powder mixed with regular particles and porous particles, inorganic and organic substances, hollow particles and solid particles [26]. It is a char-like particle with a complex shape and a porous surface formed due to the volatilization and chemical reaction of the carbon particles during the combustion process. The specific surface area is about $0.8-2.4 \mathrm{~m}^{2} \mathrm{~g}^{-1}$. Fly ash is mainly composed of $\mathrm{SiO}_{2}$ and a small amount of $\mathrm{CaO}, \mathrm{Al}_{2} \mathrm{O}_{3}, \mathrm{Fe}_{2} \mathrm{O}_{3}, \mathrm{MgO}$, and has stable physical and chemical properties and a more complex composition structure [27]. The application of fly ash to the preparation of catalytic materials is an important way to realize its high added value utilization. The change of its composition and structure has a great impact on the performance of the catalyst. Different active components and structures correspond to different reaction types and have a very wide range of adaptability [28-29]. Due to the relatively stable physical and chemical properties of fly ash, more and more researchers use it as a 
In this paper, a hydrothermal method is used to prepare Cu-BTC materials, with solid waste fly ash as the carrier. Cu-BTC is used as the active component and loaded on fly ash to prepare Cu-BTC/FA catalyst for low-temperature selective denitration. It not only improves the utilization rate of fly ash, but also reduces pollution. The purpose of improving the environment and secondary use. And most importantly, it provides a feasible basis for the industrial application of fly ash flue gas denitration loaded with Cu-BTC, which has strong practical significance.

\section{Experimental}

\subsection{Material synthesis}

\subsubsection{Optimization of synthesis conditions of Cu-BTC material}

(1) Molar ratio of substrate to ligand

Prepare a mixture of $\mathrm{Cu}\left(\mathrm{NO}_{3}\right)_{2} \cdot 3 \mathrm{H}_{2} \mathrm{O}$ and $\mathrm{H}_{3} \mathrm{TBC}$ in a ratio of 1:1. After stirring, transfer to a $100 \mathrm{~mL}$ stainless steel reactor at $150^{\circ} \mathrm{C}$. Keep it in a constant temperature oven for $15 \mathrm{~h}$. After filtering, washing and drying the product for 3 times, it was placed in a vacuum drying oven at $100^{\circ} \mathrm{C}$ and activated for 12 $\mathrm{h}$, and the blue powder obtained was sequentially denoted.

\subsubsection{Preparation of Cu-BTC/FA catalyst}

Mix fly ash and Ca-based bentonite in a 4:1 ratio, add $20 \mathrm{wt} \%$ deionized water to knead into a dough, put it into the catalyst molding extrusion device, extrude it, and place it in a $105^{\circ} \mathrm{C}$ electric blast drying oven for drying $30 \mathrm{~min}$ to obtain a columnar fly ash carrier. Weigh $0.5 \mathrm{~g}$ fly ash carrier, load a certain amount of Cu-BTC, and dry it in a vacuum drying oven for $10 \mathrm{~min}$ to obtain Cu-BTC/FA catalyst. The preparation of Cu-BTC/FA catalyst are shown in Fig. 1.

\subsection{Catalyst evaluation device}

The activity evaluation of the catalyst was carried out in a vertical denitration experimental device. Simulated gas was introduced to observe the changes of NO data. Fig. 2 is the catalyst evaluation device and experimental flow chart.

The calculation method of the denitration rate is:

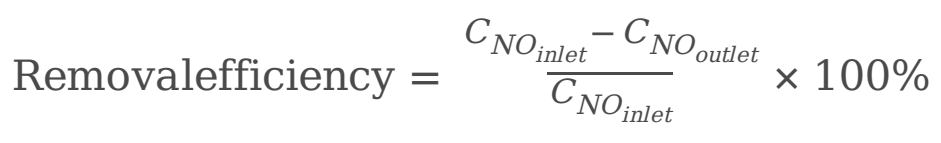

\subsection{Experimental characterization}


SEM: The model was JSM-6460LV, the working voltage was $20 \mathrm{kV}$, and the magnification was 5000 times.

XPS: The X-ray photoelectron spectrometer model used in this paper was: ESCALAB250 (manufactured by Thermo Fisher Scientific, USA). The instrument had a sensitivity of $180 \mathrm{KCPS}$, an energy resolution of $0.45 \mathrm{eV}(\mathrm{Ag})$, and an image resolution of $3 \mu \mathrm{m}$. The results of the analysis were all corrected with $\mathrm{C} 1 \mathrm{~s}$.

FT-IR: The Fourier infrared spectrometer is produced by Bruker, model is VERTEX 70.

$\mathrm{H}_{2}$-TPR: The surface characteristics of the catalyst samples were analyzed and measured with a T5076 (Tianjin Xianquan Industry and Trade Development Co., Ltd.) dynamic adsorption/desorption instrument. The catalyst sample volume is about $50 \mathrm{mg}$, the program temperature rise rate is 0.5 to $90{ }^{\circ} \mathrm{C} / \mathrm{min}$, and the reducing gas is a mixture of $95 \% \mathrm{~N}_{2}+5 \% \mathrm{H}_{2}$.

Raman: $532 \mathrm{~nm}$ argon ion laser was used to collect Raman spectra on a Renishaw IN Raman spectrometer, and experiments were performed on powder samples deposited on glass slides.

\section{Results And Discussion}

\subsection{Denitration, sulfur resistance, stability and cyclical experiments of Cu-BTC/FA catalyst}

Reaction condition: $[\mathrm{NO}]=600 \mathrm{ppm},\left[\mathrm{NH}_{3}\right]=600 \mathrm{ppm},\left[\mathrm{SO}_{2}\right]=600 \mathrm{ppm},\left[\mathrm{O}_{2}\right]=6 \%, \mathrm{~N}_{2}$ balance

Figure 3. Activity evaluation of Cu-BTC/FA catalyst

Figure 3(a) shows the effect of Cu-BTC/FA catalyst prepared with different loading ratio on the denitration performance. It can be seen that the catalyst prepared by Cu-BTC supported fly ash has a higher denitration effect. The denitration rate of the traditional fly ash blank catalyst is about $20 \%$. CuBTC/FA has the best denitration performance, the denitration rate gradually stabilizes, up to $94 \%$. The best loading ratio of the catalytic activity of Cu-BTC/FA catalysts is: $9 \%$. The reason is that the load is too small, the active sites are not evenly loaded, so the denitration effect is not optimal, but when the load is too large, the active sites occupy more positions, and the load will appear piled up, which will affect the denitration effect. Therefore, the optimal loading ratio for preparing Cu-BTC/FA is $9 \%$.

Figure 3(b) shows the stability evaluation experiment of Cu-BTC/FA catalyst under the condition of $\mathrm{SO}_{2}$. It shows that without $\mathrm{SO}_{2}$, the Cu-BTC/FA catalyst can maintain high efficiency in the removal rate of NO. When $600 \mathrm{ppm} \mathrm{SO}_{2}$ is introduced, the activity of the catalyst is affected, and the removal rate of NO is reduced. After stopping $\mathrm{SO}_{2}$, the removal rate is rebounded. The results show that the Cu-BTC/FA catalyst exhibits a higher $\mathrm{NO}$ removal rate and good stability under the condition of $\mathrm{SO}_{2}$.

Figure 3(c) shows the cyclic and stability of Cu-BTC/FA catalyst in SCR denitration under $200{ }^{\circ} \mathrm{C}$. The 
that the catalyst still maintains a denitration effect of up to $70 \%$. At the same time, a stability test of up to $6 \mathrm{~h}$ is carried out, and its denitration efficiency is maintained above $75 \%$. Therefore, it shows that the catalyst has good stability and cyclability.

\subsection{Characterization and analysis of Cu-BTC/FA 3.2.1. XRD}

Figure 4 shows the XRD patterns of Cu-BTC/FA (fresh), Cu-BTC/FA (inactived) and Cu-BTC/FA (desulfurization). Because the main components of fly ash are $\mathrm{Al}_{2} \mathrm{O}_{3}$ and $\mathrm{SiO}_{2}$. The characteristic peaks of mullite crystal form appeared at $21.23^{\circ}, 26.27^{\circ}, 35.28^{\circ}, 40.87^{\circ}$, and $60.71^{\circ}$, and the characteristic peaks of quartz quartz crystal form appeared at positions of $23.02^{\circ}, 30.92^{\circ}$ and $52.62^{\circ}$. When the Cu-BTC active component is loaded on fly ash, the Cu-BTC/FA (fresh) prepared, there is a richer copper oxide crystal structure in the sample, mainly including $\mathrm{CuO}, \mathrm{Cu}_{2} \mathrm{O}$, and the distribution of $\mathrm{CuO}$ is more than that of $\mathrm{Cu}_{2} \mathrm{O}$, the reason is that $\mathrm{Cu}_{2} \mathrm{O}$ is easy to decompose to produce $\mathrm{CuO}$. $\mathrm{CuO}$ and $\mathrm{Cu} 2 \mathrm{O}$ have no obvious diffraction peaks, indicating that these two oxides are amorphous or uniformly dispersed on the surface of the catalyst [30]. The crystal structure on the surface of Cu-BTC/FA (inactived) catalyst is different than that of Cu-BTC/FA (Fresh), and the XRD peak pattern has obvious changes, especially at $12^{\circ}, 14.3^{\circ}$, $18.1^{\circ}$. According to the previous research of the research group, these three peaks are special peaks of Cu-BTC. During the reaction, the characteristic peaks reacted and CuO was partially generated, indicating that the crystal structure of Cu-BTC was destroyed and the catalyst structure after the reaction changed, but after $20^{\circ}$, the catalyst structure did not change significantly. For the sulfur-resistant Cu-BTC/FA (desulfurization) catalyst, the peak shape changes slightly. The peaks of $\mathrm{Cu}_{2} \mathrm{~S}, \mathrm{CuS}$ and $\mathrm{Cu}_{2} \mathrm{SO}_{4}$ appeared in the XRD pattern. At $37.5^{\circ}, 45.8^{\circ}, 47.1^{\circ}, 53.9^{\circ}$ are the diffraction peaks of $\mathrm{Cu}_{2} \mathrm{~S}$, at $20.5^{\circ}, 36.7^{\circ}$, $38.1^{\circ}$ are the diffraction peaks of $\mathrm{Cu}_{2} \mathrm{SO}_{4}$, at $18.1^{\circ}, 20.5^{\circ}, 26.3^{\circ}, 33.7^{\circ}, 50^{\circ}$ are CuS the diffraction peaks. The results show that $\mathrm{SO}_{2}$ reacts preferentially with the active components of the catalyst, occupying active sites and introducing new impurities, which is consistent with the decrease in the denitration effect of the Cu-BTC/FA catalyst caused by the introduction of $\mathrm{SO}_{2}$.

\subsubsection{FTIR}

Figure 5 shows the characterization of catalytic species on the surface of Cu-BTC/FA (fresh), Cu-BTC/FA (inactived) and Cu-BTC/FA (desulfurization) catalysts. Comparing Cu-BTC/FA before and after denitration, the absorption peak at $1644 \mathrm{~cm}^{-1}$ is the (CO) stretching vibration absorption peak in the ligand DMF, and the absorption peak at $1447 \mathrm{~cm}^{-1}$ is the vibration absorption peak of the benzene ring skeleton structure. The absorption peak at $1371 \mathrm{~cm}^{-1}$ is the symmetrical absorption peak of (CO-O) in $1,3,5$ trimellitic acid. These peaks are all produced by the synthesis of the solvent and experimental drugs added in the preparation process of the active component Cu-BTC in the reactor. The Si-O vibration peak of fly ash raw material appeared near $1041 \mathrm{~cm}^{-1}$, and the $\mathrm{Al}-\mathrm{O}$ vibration peak of $\mathrm{AlO}_{6}$ appeared near $540 \mathrm{~cm}^{-1}$. These telescopic vibration peaks are all related to the important component of mullite in fly 
the peaks at $1644 \mathrm{~cm}^{-1}, 1447 \mathrm{~cm}^{-1}$, and $1371 \mathrm{~cm}^{-1}$ disappeared. The reason is that the three peaks are mainly the active component $\mathrm{Cu}-\mathrm{BTC}$ peak, and in the catalytic reaction, the characteristic peak of the active component reacts with $\mathrm{NH}_{3}$ or $\mathrm{NO}$, causing the peak to weaken or even disappear. When $\mathrm{SO}_{2}$ is introduced, compared with the infrared spectrum of Cu-BTC/FA after denitration, there are almost no new peaks, and the peak shapes are basically similar, which further proves that the sulfur resistance is good [31]. This can be well combined with XRD to explain its denitration mechanism.

\subsubsection{SEM}

Figure 6 is the electron micrograph of the Cu-BTC/FA catalyst before and after denitration and after sulfur resistance. Figure 6(a) is the Cu-BTC/FA (fresh) catalyst, $6(\mathrm{~b})$ is the Cu-BTC/FA (inactived) catalyst, and 6(c) is the Cu-BTC/FA (desulfurization) catalyst. It can be seen that the Cu-BTC/FA (inactived) catalyst has reduced the gaps between particles, agglomeration has occurred on the surface of the catalyst, and the distribution of surface components is not uniform even before the reaction. The reason is that the ammonium salt produced during the SCR reaction covers the surface of the catalyst, reducing the gap between the particles and the pore structure of the catalyst. After a certain amount of $\mathrm{SO}_{2}$ is introduced into the system, the active components in the catalyst will react with the element $\mathrm{S}$ to form sulfur salts, which makes the reduction of the pore structure of the catalyst surface more obvious. Therefore, there are still small particles on the catalyst surface as fresh catalysts. The reduction of the voids between the particles comes from the aggregation of sulfide salts and sulfate salts.

\subsubsection{XPS}

In order to further reveal the element composition and valence state of the Cu-BTC/FA catalyst surface, the Cu-BTC/FA catalyst with better denitration and anti-sulfur effects was characterized by XPS. As shown in Fig. 7, the XPS full spectrum confirmed that the catalyst surface contains $\mathrm{Cu}, \mathrm{O}$ and $\mathrm{C}$ elements. The characteristic peak position of C $1 \mathrm{~s}$ is $284.6 \mathrm{eV}$ as the measurement standard for XPS characterization.

It can be seen from the Cu2p XPS spectrum that the Cu2p binding energy of the Cu-BTC/FA catalyst is composed of $\mathrm{Cu}_{2} \mathrm{P}_{3 / 2}, \mathrm{Cu}_{2} \mathrm{P}_{1 / 2}$, and the characteristic peaks of $895 \mathrm{eV}$ and $979 \mathrm{eV}$ are attributed to $\mathrm{Cu}_{2} \mathrm{P}_{3 / 2}, \mathrm{Cu} 2 \mathrm{P}_{1 / 2}$. The sample has an obvious satellite peak at the binding energy of 938.8-944.2 eV, which is a characteristic peak of $\mathrm{Cu}^{2}+\mathrm{d}^{8}$ orbital electron arrangement, indicating that the surface of the sample contains $\mathrm{Cu}^{2+}$ species. It is reported in the literature that in the SCR denitration reaction, $\mathrm{NH}_{3}$ and NO molecules are easily adsorbed on the $\mathrm{Cu}^{2+}$ and $\mathrm{Cu}^{+}$on the surface of the catalyst to react [32-33]. At the same time, $\mathrm{Cu}^{2+}$ and $\mathrm{Cu}^{+}$are also considered to be the main metal active sites in the SCR reaction. Fitting the $\mathrm{Cu}_{2} \mathrm{P}_{3 / 2}$ and $\mathrm{Cu} 2 \mathrm{P}_{1 / 2}$ peaks respectively, it can be found that the sample surface contains $\mathrm{Cu}$ species, that is, $\mathrm{Cu}^{2+}$ and $\mathrm{Cu}^{+}$coexist, and the relative content of the two-valence species is not much different. After the reaction, the positions of the main peaks all shifted to high binding energy, and the shift was small after anti-sulfur denitration [34]. It is speculated that $\mathrm{SO}_{2}$ binds to the surface-active sites of the motal orranir framewnrk recultinn in a cmall chift of the main peak. 
Fitting the 01s spectra before and after the reaction showed that there were two peaks at $532 \mathrm{eV}$ and $530.8 \mathrm{eV}$. The peak at $532 \mathrm{eV}$ mainly exists in the form of $\mathrm{O}^{2-}$ or $\mathrm{O}^{-}$, corresponding to the surface adsorbed oxygen species $\mathrm{O}_{\beta}$, the peak at $530.8 \mathrm{eV}$ mainly exists in the form of $\mathrm{O}^{2-}$, corresponding to the lattice oxygen species $\mathrm{O}_{\mathrm{a}}$. According to literature reports, adsorbed oxygen is the most active reactive species in catalytic reactions and can significantly promote the oxidation-reduction reaction on the catalyst surface in SCR reactions. Based on the area integration of these two peaks, it can be calculated that the relative concentration of $\mathrm{O}_{\beta} /\left(\mathrm{O}_{\alpha}+\mathrm{O}_{\beta}\right)$ in the Cu-BTC/FA material is $29.9 \%$. Because the surface adsorbed oxygen $\mathrm{O}_{\beta}$ has better fluidity, and can be used as an electron acceptor to react with the reaction gas NO. Therefore, Cu-BTC/FA with a higher $\mathrm{O}_{\beta} /\left(\mathrm{O}_{\mathrm{a}}+\mathrm{O}_{\beta}\right)$ ratio is presumed to have higher SCR denitration performance [35]. This explains the excellent denitration performance of the catalyst in the above activity test.

\subsection{5. $\mathrm{H}_{2}$-TPR and Raman}

Figure 8(a) is the $\mathrm{H}_{2}$-TPR experiment of the catalyst. It can be seen that the catalyst has $\operatorname{similar} \mathrm{H}_{2}$ reduction peaks before and after the reaction. Combined with the Cu-BTC thermogravigram, it can be seen that the catalyst sample has only one obvious reduction peak in the low temperature range of 0 $350^{\circ} \mathrm{C}$, and the peak that appears is caused by the reduction of $\mathrm{Cu}^{2+}$ to $\mathrm{Cu}{ }^{+}$. When the temperature is higher than $400^{\circ} \mathrm{C}$, the Cu-BTC structure will collapse [36]. The reduction peak of the catalyst after the reaction disappears at $0-350^{\circ} \mathrm{C}$. The reason is that the characteristic peak of Cu-BTC participates in the catalytic reaction during the denitration process, resulting in the disappearance of the characteristic peak. The three obvious reduction peaks appearing at temperatures above $500^{\circ} \mathrm{C}$ are mainly caused by the reduction of other elements ( $\mathrm{Si}, \mathrm{Al}, \mathrm{etc}$.) in the catalyst carrier fly ash.

Figure $8(\mathrm{~b})$ is the raman characterization diagram of Cu-BTC/FA catalyst prepared under the optimal conditions. The characteristic peaks in the low frequency region of $100-600 \mathrm{~cm}^{-1}$ are attributed to the $\mathrm{Cu}_{2} \mathrm{C}_{4} \mathrm{O}_{8}$ metal cluster in the $\mathrm{Cu}-\mathrm{BTC}$ catalyst structure. Among them, there is a strong structural characteristic peak near $101 \mathrm{~cm}^{-1}$, which is attributed to the stretching vibration of the Cu-Cu bond. The attribution of the characteristic peaks at $230 \mathrm{~cm}^{-1}$ and $548 \mathrm{~cm}^{-1}$ has not been accurately confirmed. The characteristic peaks of $730-1800 \mathrm{~cm}^{-1}$ in the high frequency region are attributed to the internal organic components of the Cu-BTC catalyst, and the characteristic peaks of $1578 \mathrm{~cm}^{-1}$ and $1475 \mathrm{~cm}^{-1}$ are attributed to the symmetrical and asymmetrical stretching vibration peaks of -CO0. This shows that 1,3,5 trimellitic acid is completely deprotonated. The characteristic peaks at $1097 \mathrm{~cm}^{-1}$ and $1001 \mathrm{~cm}^{-1} \mathrm{can} \mathrm{be}^{-1}$ attributed to the vibrational stretching peak of the $\mathrm{C}=\mathrm{C}$ bond on the benzene ring, and the characteristic peak near $825 \mathrm{~cm}^{-1}$ is the bending vibration peak of the $\mathrm{C}-\mathrm{H}$ bond on the benzene ring. The above results show that the Cu-BTC material prepared by hydrothermal synthesis method is successfully synthesized and the structure is complete.

\subsubsection{NO reaction process}


Based on the XPS and $\mathrm{H}_{2}$-TPR characterization results, it is speculated that the $\mathrm{NH}_{3}$-SCR reaction process with $\mathrm{Cu}-\mathrm{BTC} / \mathrm{FA}$ as the catalyst is as follows:

\begin{tabular}{|l|}
\hline $\mathrm{NH}_{3}(\mathrm{~g})+\mathrm{Cu}^{+} \rightarrow \mathrm{NH}_{3}(\mathrm{a})$ \\
$\mathrm{NO}(\mathrm{g})+\mathrm{Cu}^{2+} \rightarrow \mathrm{NO}(\mathrm{a})$ \\
$\mathrm{NO}(\mathrm{a})+\mathrm{Cu}^{2+}+\mathrm{NH}_{3}(\mathrm{a}) \rightarrow \mathrm{N}(\mathrm{a})+\mathrm{O}(\mathrm{a})+\mathrm{Cu}^{+}+\mathrm{NH}_{3}(\mathrm{a})$ \\
$\mathrm{NO}(\mathrm{a})+\mathrm{Cu}^{+} \mathrm{NH}_{3}(\mathrm{a}) \rightarrow \mathrm{N}(\mathrm{a})+\mathrm{O}(\mathrm{a})+\mathrm{Cu}^{0}+\mathrm{NH}_{3}(\mathrm{a})$ \\
\hline $\mathrm{NH}_{3}(\mathrm{a})+\mathrm{O}(\mathrm{a}) \rightarrow \mathrm{NO}_{2}(\mathrm{~g})$ \\
\hline $\mathrm{N}(\mathrm{a})+\mathrm{N}(\mathrm{a}) \rightarrow \mathrm{N}_{2}(\mathrm{~g})$ \\
\hline $\mathrm{O}(\mathrm{a})+\mathrm{Cu}^{+} / \mathrm{Cu}^{0} \rightarrow \mathrm{Cu}^{2+}$
\end{tabular}

In the low temperature stage, that is, the reaction (1) and (2) stage, $\mathrm{NO}$ and $\mathrm{NH}_{3}$ gas molecules are adsorbed by $\mathrm{Cu}^{2+} / \mathrm{Cu}^{+}$ions respectively, and active $\mathrm{NO}(\mathrm{a})$ and $\mathrm{NH}_{3}(\mathrm{a})$ species are formed the same time. With the increase of temperature, namely the reaction (3) stage, the active $\mathrm{NO}(\mathrm{a})$ is decomposed into active $\mathrm{N}(\mathrm{a})$ and $\mathrm{O}(\mathrm{a})$ species, and $\mathrm{Cu}^{2+}$ is reduced to $\mathrm{Cu}^{+}$by $\mathrm{NH}_{3}$. When the temperature continues to rise, that is, the reaction (4) stage, the active NO continues to decompose the $\mathrm{N}(\mathrm{a})$ and $\mathrm{O}(\mathrm{a})$ species, while $\mathrm{Cu}^{+}$is reduced to $\mathrm{Cu}^{0}$ by $\mathrm{NH}_{3}$. In the reaction (5) and (6) stages, $\mathrm{NH}_{3}(\mathrm{a})$ is oxidized by the active $\mathrm{O}(\mathrm{a})$ species to generate $\mathrm{NO}_{2}$, and $\mathrm{N}(\mathrm{a})$ is combined to generate $\mathrm{N}_{2}$. In the reaction (7) stage, $\mathrm{Cu}^{+}$and $\mathrm{Cu}^{0}$ react with the active species to re-convert to high-valence $\mathrm{Cu}^{2+}$, so that the SCR reaction can continue.

\section{Conclusion}

The solid waste fly ash was used as a carrier, and Cu-BTC was loaded on the surface of columnar fly ash as an active component to prepare a Cu-BTC/FA catalyst. Use a variety of characterization methods to analyze, determine the morphology, structure and properties of the catalyst, and analyze its impact on the denitration performance. The results show: The optimal Cu-BTC/FA was prepared and it was proved to have excellent catalytic activity in the temperature range of $100-300{ }^{\circ} \mathrm{C}$. When the active component $\mathrm{Cu}-$ BTC loading ratio is $9 \%$, the denitration effect is as high as $94 \%$. The denitration performance is excellent and has strong stability. The Cu-BTC/FA catalyst also shows a high NO removal rate and good stability under the condition of $\mathrm{SO}_{2}$. The catalyst has good stability and cyclability. After 6 tests, the activity of the catalyst can still be maintained about $72 \%$. Also, stability test of up to $6 \mathrm{~h}$ is carried out, and its denitration efficiency is maintained above $75 \%$. According to XPS and $\mathrm{H}_{2}$-TPR test results, the main metal active species of the catalyst is $\mathrm{Cu}^{2+} / \mathrm{Cu}^{+}$. When the temperature continues to rise, the main active 
species is $\mathrm{Cu}^{+} / \mathrm{Cu}^{0}$. The interaction between $\mathrm{Cu}$ ions is conducive to the generation of more metal active sites.

\section{Declarations}

\section{Author contributions}

Conceptualization, Shu Hao; Methodology, Yuling Liu; Software, Shu Hao; Validation, Shu Hao; Investigation, Shu Hao; Data Curation, Shu Hao; Writing-Original Draft Preparation, Shu Hao; WritingReview \& Editing, Shu Hao.

\section{Conflicts of interest}

There are no conflicts to declare.

\section{Acknowledgements}

This work is supported by the National Natural Science Foundation of China [51578452]; Key R \& D Program in Shaanxi Province [2020SF-354]; Open Fund of Shaanxi Key Laboratory of Geological Support for Coal Green Exploitation [NO. DZBZ2020-08].

\section{References}

1. D.R.K.,D.R. Kumar., A. Joshi, SY, An. HM, Cunningham. MJ and Currier. NW, A modeling and experimental study on hydrothermal aging deactivation of NO oxidation activity on Pt-Pd catalyst. Appl. Catal. B-Environ. 283, 119655 (2021). https://doi.org/10.1016/j.apcatb.2020.119655

2. J.Y. Chen, P. Fu, D.F. Lv, Y. Chen, M.L. Fan., J.L. Wu, Meshram, A, Mu. B, Li. X and Xia. Q.B, Unusual positive effect of $\mathrm{SO}_{2}$ on $\mathrm{Mn}$-Ce mixed-oxide catalyst for the SCR reaction of $\mathrm{NOx}$ with $\mathrm{NH}_{3}$. Chem. Eng. J. 407, 127071 (2021). https://doi.org/10.1016/j.cej.2020.127071

3. C.M.,J.L. Liu., Y. Guo, X.R and Chu. J.W, Decomposition of NO in automobile exhaust by plasmaphotocatalysis synergy. Environ. Sci. Pollut. R. 21, 1242-1247 (2014). https://doi.org/10.1007/s11356-013-2021-2

4. A.A. Najafpoo, A.J. Jafari, A. Hosseinzadeh, R.K. Jazani, H. Bargozin, Optimization of non-thermal plasma efficiency in the simultaneous elimination of benzene toluene ethyl-benzene and xylene from polluted airstreams using response surface methodology. Environ. Sci. Pollut. R. 25, 233-241 (2018). https://doi.org/10.1007/s11356-017-0373-8

5. D.J. Vogel, Z.R. Lee, C.A. Hanson, S.E. Henkelis, C.M. Smith, T.M. Nenoff, Dixon, D.A and Rimsza. J.M, Predictive Acid Gas Adsorption in Rare Earth DOBDC Metal-Organic Frameworks via Complementary Cluster and Periodic Structure Models. J. Phys. Chem. C 124, 26801-26813 (2020). https://doi.org/10.1021/acs.jpcc.0c08282 
6. Q. Zhao., B.B. Chen, L.J. Wang. M. X.B, Crocker, C. Shi, Insights into the structure-activity relationships of highly efficient CoMn oxides for the low temperature NH3-SCR of NOx. Appl. Catal. B-Environ. 277, 119215 (2020). https://doi.org/10.1016/j.apcatb.2020.119215

7. V.A. Italiano. C, M.A. Ashraf, Pino, L and Specchia. S, Syngas production by steam and oxy-steam reforming of biogas on monolith-supported CeO2-based catalysts. Int. J. Hydrogen. Energ. 43, 11731-11744 (2018). https://doi.org/10.1016/j.jhydene.2017.11.140

8. D.M. Meng, Q. Xu, Y.L. Jiao, Spinel structured CoaMnbOx mixed oxide catalyst for the selective catalytic reduction of NOx with NH3. Appl. Catal. B-Environ 221, 652-663 (2018). https://doi.org/10.1016/j.apcatb.2017.09.034

9. A.J.N. Ramalingam. R.J. Al-Lohedan. H.A. Khoerunnisa. F, T.C. Ling, E.P. Ng, Selective synthesis of dioxolane biofuel additive via acetalization of glycerol and furfural enhanced by MCM-41-alanine bifunctional catalyst. Fuel. 288, 119573 (2021). https://doi.org/10.1016/j.fuel.2020.119573

10. M.Y. Chen, M.M. Zhao, F.S. Tang, L. Ruan, and Yang. B, Effect of Ce doping into V2O5-WO3/TiO2 catalysts on the selective catalytic reduction of NOx by NH. J. Rare. Earth. 35, 1206-1215 (2017). https://doi.org/10.1016/j.jre.2017.06.004

11. L. Qin., X.J. Gao, Q.Y. Li, Influences of coal fly ash containing ammonium salts on properties of cement paste. J. Environ. Manage. 249, 109374 (2019). https://doi.org/10.1016/j.jenvman.2019.109374

12. S.A. Shanthi. K, S.D. Babu. C.M. Srinivasan.V. V, R.V. Thirukumaran. P, Shakilaparveen, A and Balasubramanian. R, Effective removal of automobile exhausts over flower-like Ce1-xCuxO2 nanocatalysts exposed active $\{100\}$ plane. J. Rare. Earth. 36, 603-612 (2017). https://doi.org/10.1016/j.jre.2017.12.006

13. Q.H. Yan, X.T. Hou, G.C. Liu, Y.R. Li, T.Y. Zhu, Y.J. Xin, Q. Wang, Recent advances in layered double hydroxides (LDHs) derived catalysts for selective catalytic reduction of $\mathrm{NOx}$ with $\mathrm{NH}_{3}$. J. Hazard. Mater. 400, 123260 (2020). https://doi.org/10.1016/j.jhazmat.2020.123260

14. Z.L. Shu. H, Y. Jia, F. Lei. Z, Bai., K.W. Qi. L.B, Shang. J and Chao. Wei, Study on denitration and sulfur removal performance of Mn-Ce supported fly ash catalyst, Chemosphere. 128646 (2021). https://doi.org/10.1016/j.chemosphere.2020.1286

15. N. Jaegers, L.J.K. R, Y. He, W.E. Dixon. D.A, Y. Vasiliu. M, Chen., C.M. Wang., M.Y. Hu, K.T. Mueller, I.E. Wachs, Wang. Y and Hu. J.Z, Mechanism by which Tungsten oxide promotes the activity of supported V205/TiO2 catalysts for NOX abatement: structural effects revealed by V-51 MAS NMR spectroscopy, Angew. Chem. Int. Edit. 58, 12609-12616 (2019).

https://doi.org/10.1002/anie.201904503

16. Z.X. Ren, H.L. Zhang, G.Y. Wang, Y.C. Pan, Yu. Z.W and H.M. Long, Effect of Calcination Temperature on the Activation Performance and Reaction Mechanism of Ce-Mn-Ru/TiO 2 Catalysts for Selective Catalytic Reduction of $\mathrm{NO}$ with $\mathrm{NH}_{3}$, Acs. Omega. 5, 33357-33371 (2020). https://doi.org/10.1021/acsomega.0c05194 
17. P. Kechagia., K.D. Bartzas., G. Peppas. A, M. Samouhos., Deligiannis. S and Tsakiridis. P.E, Waste marble dust and recycled glass valorization in the production of ternary blended cements, Sci. Total. Environ. 761, 143224 (2021). https://doi.org/10.1016/j.scitotenv.2020.143224

18. L.N. Gan, K.Z. Li, H.J.Y. Niu, J.J. Peng. Y, Chen., Y.D. Huang, J.H. Li, Simultaneous removal of NOx and chlorobenzene on $\mathrm{V}_{2} \mathrm{O}_{5} / \mathrm{TiO}_{2}$ granular catalyst: Kinetic study and performance prediction. Front. Env. Sci. Eng. 15, 70 (2021). https://doi.org/10.1007/s11783-020-1363-5

19. N. Czuma, K. Zarebska, M. Motak, M.E. Galvez, Da and Costa. P, Ni/zeolite X derived from fly ash as catalysts for $\mathrm{CO}_{2}$ methanation. Fuel. 267, 117139 (2020). https://doi.org/10.1016/j.fuel.2020.117139

20. Y.F. Qi, X.W. Shan, M.T. Wang, D.D. Hu, Y.B. Song, P.L. Ge, J. Wu, Study on Low-Temperature SCR Denitration Mechanisms of Manganese-Based Catalysts with Different Carriers. Water. Air. Soil. Poll. 231, 289 (2020). https://doi.org/10.1007/s11270-020-04644-5

21. W.M.,L.D. Maurin., G. Stock. N and M.T. Wharmby, Rietveld Refinement of MIL-160 and Its Structural Flexibility Upon H2O and N-2 Adsorption. Eur. J. Inorg. Chem. 32, 3626-3632 (2018). https://doi.org/10.1002/ejic.201800323

22. Z.L. Shu. H, Y. Jia., Zhang. L and D. Xu, Study on Solid Waste Pyrolysis Coke Catalyst for Catalytic Cracking of Coal Tar. Int. J. Hydrogen. Energ. 45, 19280-19290 (2020). https://doi.org/10.1016/j.ijhydene.2020.05.075

23. J.M.,W.B. Beale. A.M. Pischinger. S and R. Palkovits, Comparison of Cu-Mg-Al-O-x and Cu/Al2O3 in selective catalytic oxidation of ammonia (NH3-SCO). Catal. Commun. 110, 5-9 (2018). https://doi.org/10.1016/j.catcom.2018.03.003

24. Felix. D and D. Murgulet, Nitrate isotopic composition of sequential Hurricane Harvey wet deposition: Low latitude NOx sources and oxidation chemistry. Atmos. Environ. 238, 117748 (2020). https://doi.org/10.1016/j.atmosenv.2020.117748

25. S. Li, H.Y. Gong., H.Y. Hu, H.M. Liu, Y.D. Huang, FuB. Wang. L.L and H. Yao, Re-using of coal-fired fly ash for arsenic vapors in-situ retention before SCR catalyst: Experiments and mechanisms. Chemosphere. 254, 126700 (2020). https://doi.org/10.1016/j.chemosphere.2020.126700

26. S.C. Schroeder. W. Yang. S.S. Nystrom. A, S. Cai. Z, Subramanian, S.J. Li, M.A. Gundersen, S.B. Cronin, Plasma-enhanced NOx remediation using nanosecond pulsed discharges in a water aerosol matrix, Fuel. Process. Technol. 208, 106521 (2020). https://doi.org/10.1016/j.fuproc.2020.106521

27. W.B. Yang., F. Song. Z.J and L.S. Sun, Removal of $\mathrm{Hg}-\mathrm{O} \mathrm{NO}$ and $\mathrm{SO}_{2}$ by the surface dielectric barrier discharge coupled with Mn/Ce/Ti-based catalyst. Environ. Sci. Pollut. R. (2021). https://doi.org/10.1007/s11356-020-11886-7

28. G.F. Gholami. Z, T.M. Vavrunkova., V, Mirzaei, S and Vakili. M, O-2 over M@La-Fe/AC (M = Mn Ce. Catalyst, Catalysts. 10, 1322 (2020). https://doi.org/10.3390/catal10111322

29. S.K.P. Veerapandian, Z.P. Ye, J.M. Giraudon, De, Geyter. N, Morent. R and Lamonier. J.F, A plasma assisted Cu-Mn mixed oxide catalysts for trichloroethylene abatement in moist air. J. Hazard. Mater. 
30. I.C. Balzarotti. R, A. Vita., S. Latorrata, Fabiano. C, Pino. L and Cristiani. C, Preparation of structured catalysts with $\mathrm{Ni}$ and $\mathrm{Ni} \mathrm{Rh} / \mathrm{CeO} 2$ catalytic layers for syngas production by biogas reforming processes. Catal. Today 273, 3-11 (2019). https://doi.org/10.1016/j.cattod.2016.01.037

31. R.M. Rooney. K. Hara, S. Nakatani, Measurement of automobile NO from bag and continuous stream by quantum cascade laser spectroscopy. Int. J. Engine. Res. 20, 261-273 (2019). https://doi.org/10.1177/1468087417750937

32. ShuH. Liu. Y.L. Jia, Y, Shear Stress on the Structure Control of a Supported Fly Ash-Based Catalyst and Its Application in SCR Denitration. ChemistrySelect. 6, 7950-7955 (2021). https://doi.org/10.1002/slct.202101770

33. Q. Song., H.Y. Zhao, S.Q. Chang, F. Yang. L, Zou., X.Q. Shu, P. Zhang, Study on the catalytic pyrolysis of coal volatiles over hematite for the production of light tar. J. Anal. Appl. Pyrol. 151, 104927 (2020). https://doi.org/10.1016/j.jaap.2020.104927

34. L.J.W. Wang. J.N. Zhu. L, X. Chen, A high-safety and multifunctional MOFs modified aramid nanofiber separator for lithium-sulfur batteries. Chem. Eng. J. 411, 128540 (2021). https://doi.org/10.1016/j.cej.2021.128540

35. Q. Song., H.Y. Zhao, J.W. Jia, L. Yang, W. Lv., B.J.W. Shu. X.Q. Gu. Q.X. Zhang, P, Pyrolysis of municipal solid waste with iron-based additives: A study on the kinetic, product distribution and catalytic mechanisms. J. Clean. Prod. 258, 120682 (2020).

https://doi.org/10.1016/j.jclepro.2020.120682

36. G.S. Mohammad-Pour, K.O. Hatfield, D.C. Fairchild, K. Hernandez-Burgos, Rodriguez-LopezJ. UribeRomo, F.J, A Solid-Solution Approach for Redox Active Metal-Organic Frameworks with Tunable Redox Conductivity. J. Am. Chem. Soc. 141, 19978-19982 (2019).

https://doi.org/10.1021/jacs.9b10639

\section{Figures}

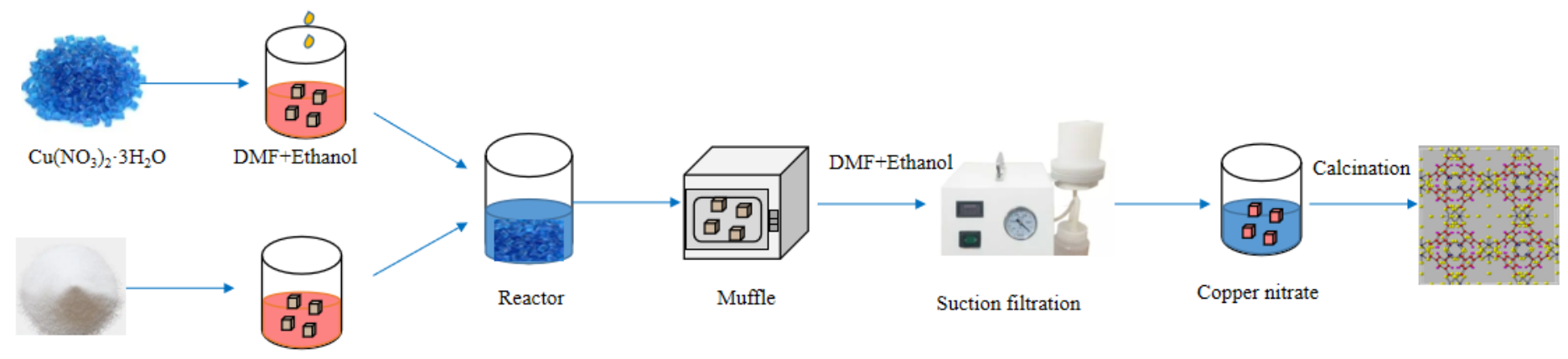

$\mathrm{C}_{9} \mathrm{H}_{6} \mathrm{O}_{6}$

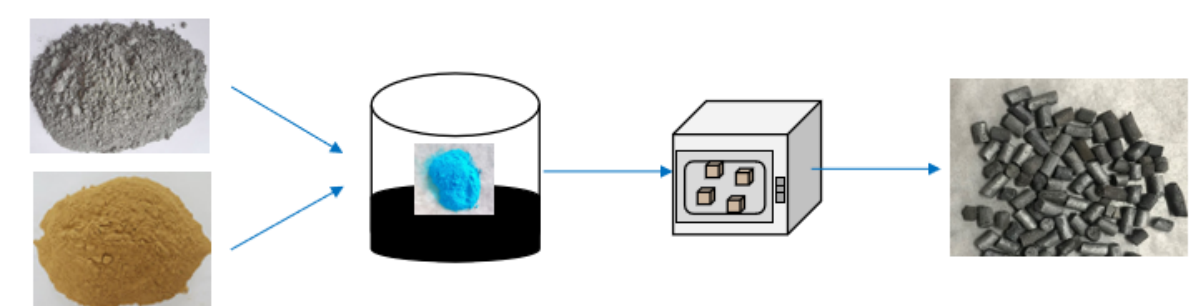


Figure 1

The preparation of Cu-BTC/FA catalyst

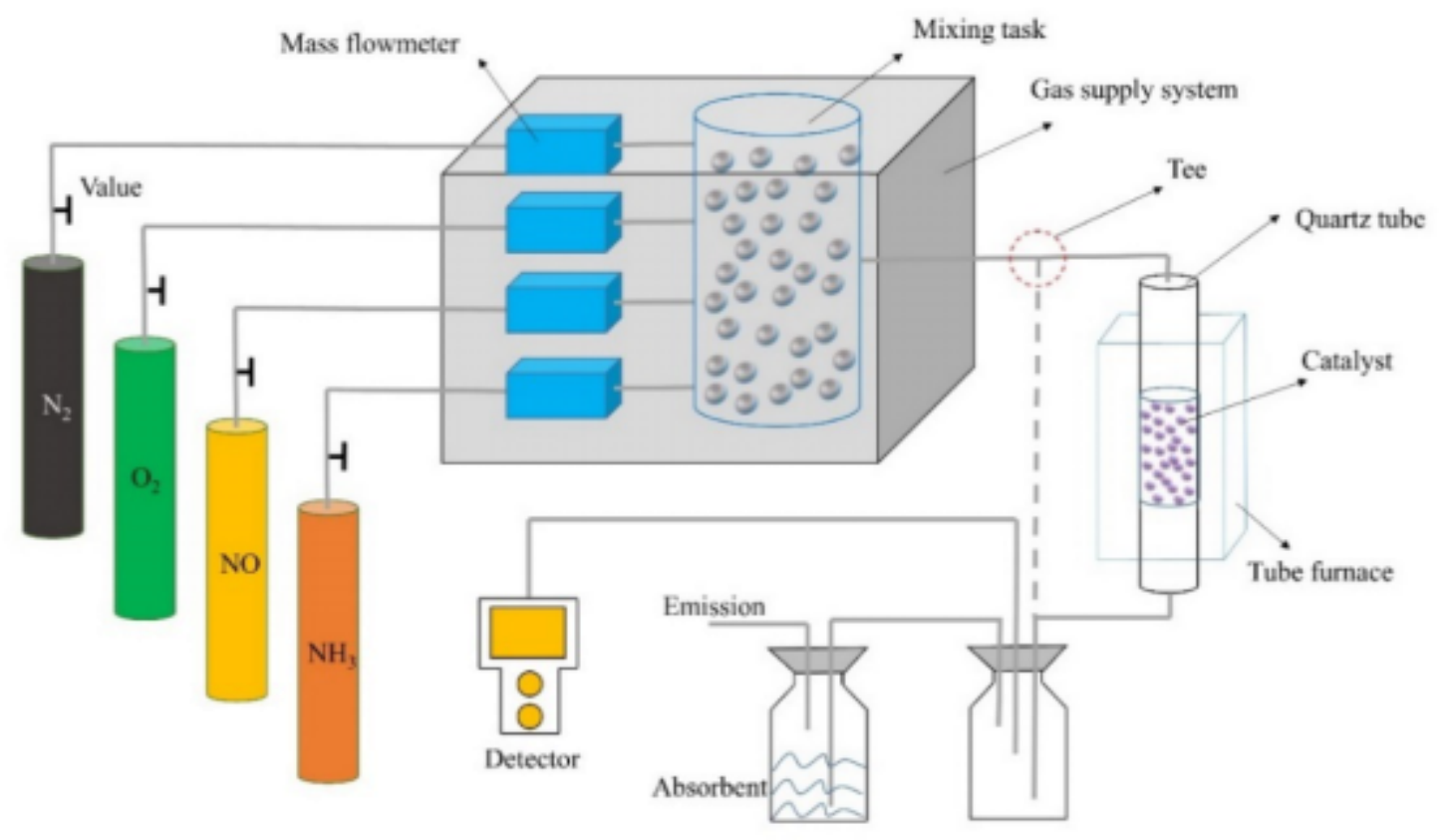

Figure 2

Catalyst evaluation device
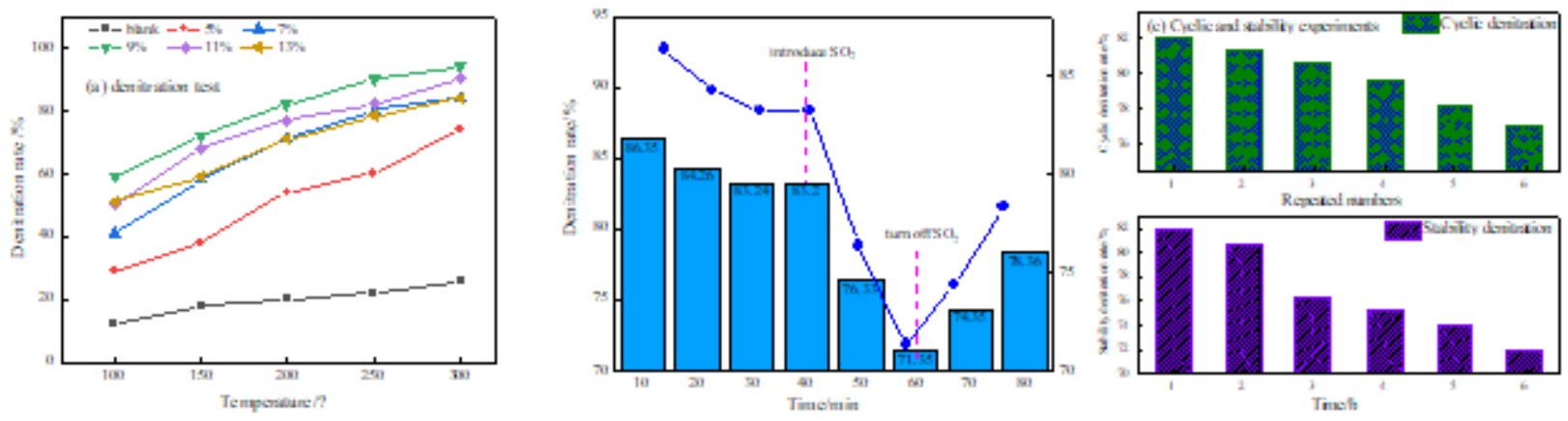

Reaction condition: $[\mathrm{NO}]=600 \mathrm{ppm},\left[\mathrm{NH}_{3}\right]=600 \mathrm{ppm},\left[\mathrm{SO}_{2}\right]=600 \mathrm{ppm},\left[\mathrm{O}_{2}\right]=6 \%, \mathrm{~N}_{2}$ bal ance

Figure 3

Activity evaluation of Cu-BTC/FA catalyst 


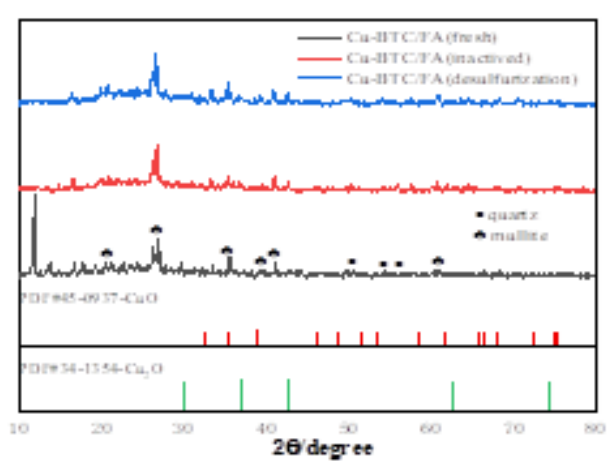

Figure 4

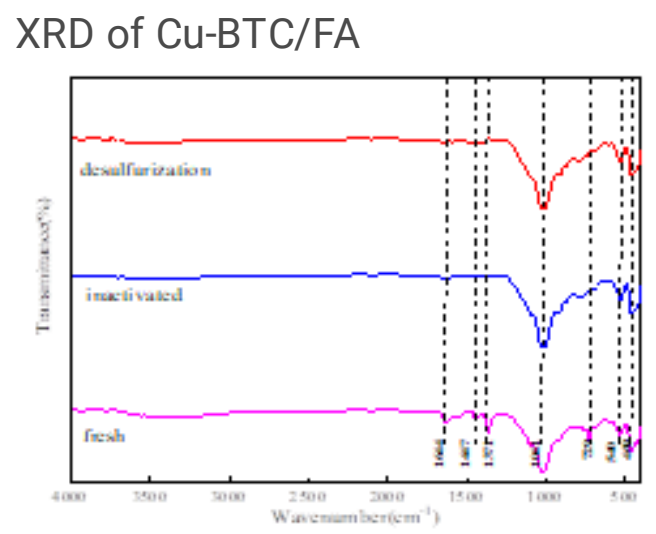

Figure 5

FT-IR of Cu-BTC/FA
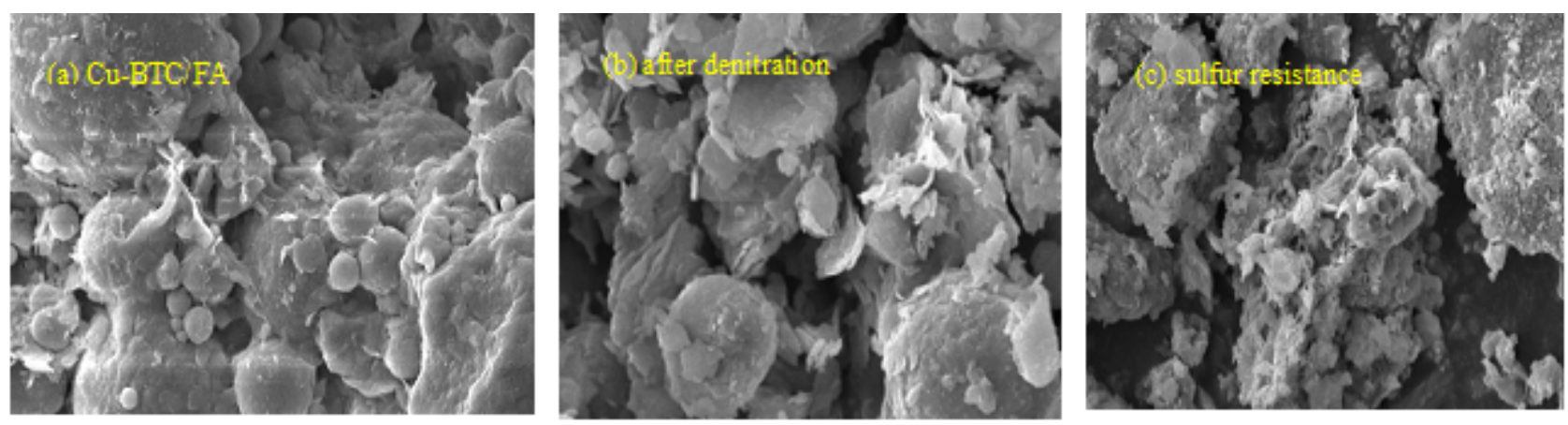

Figure 6

SEM of Cu-BTC/FA 

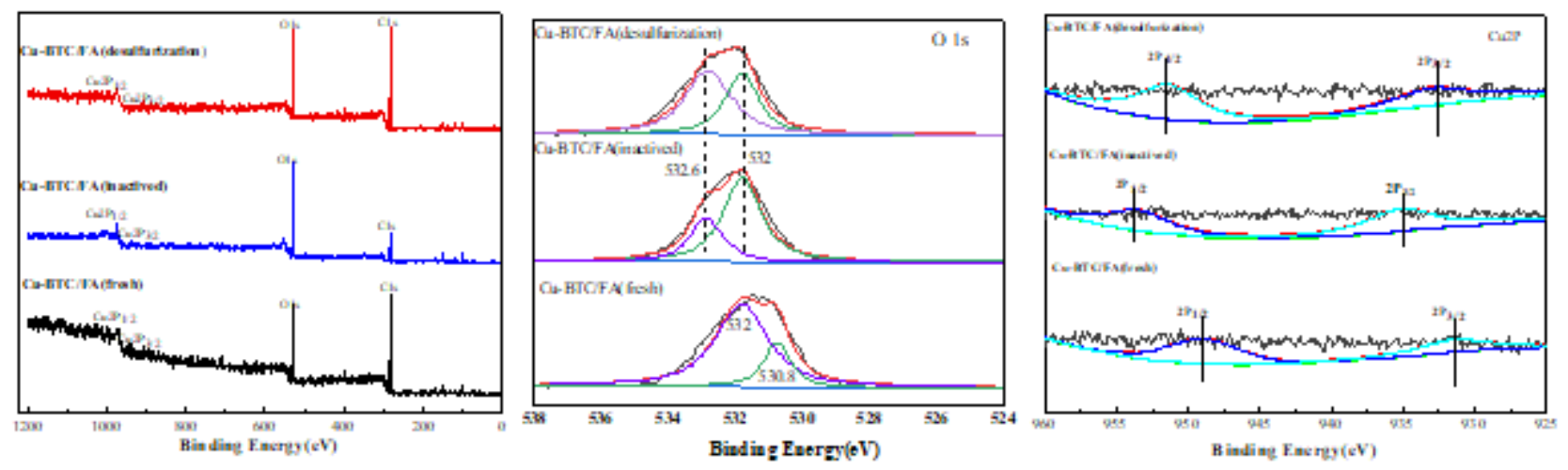

Figure 7

XPS of Cu-BTC/FA catalyst

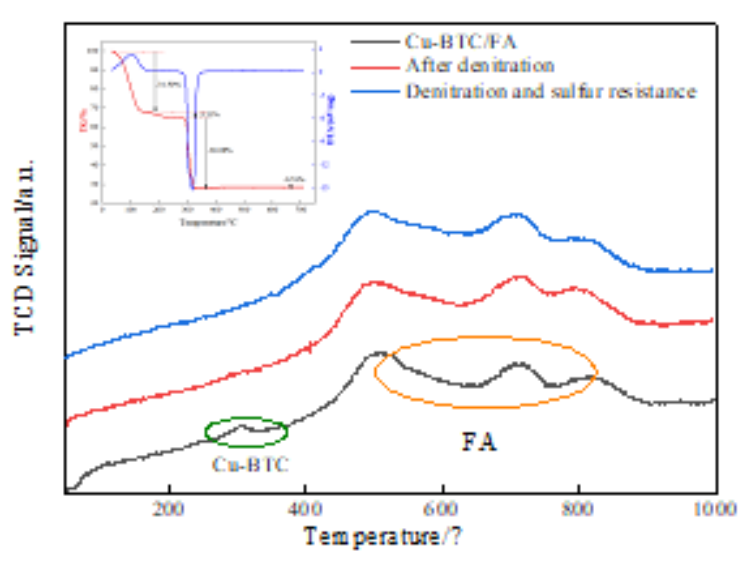

(a) $\mathrm{H}_{2}$-TPR of $\mathrm{Cu}-\mathrm{BTC} / \mathrm{FA}$

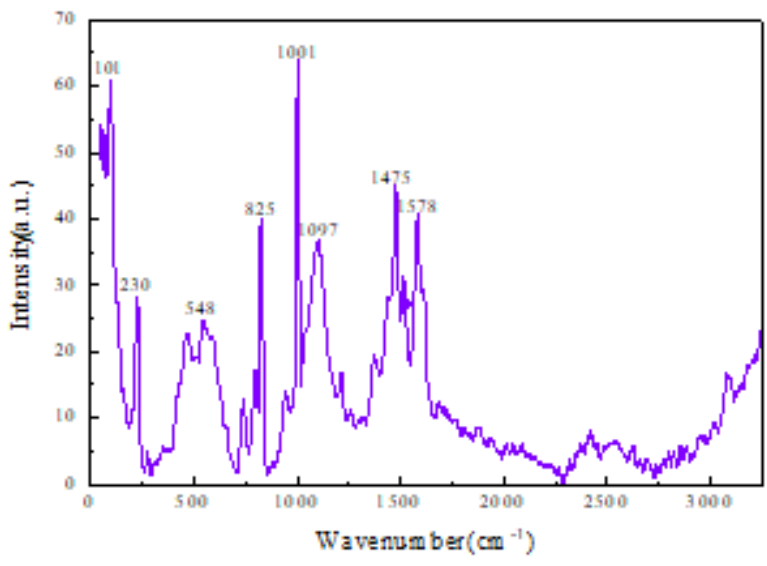

(b) Raman of Cu-BTC/FA

Figure 8

H2-TPR and raman of Cu-BTC/FA catalyst

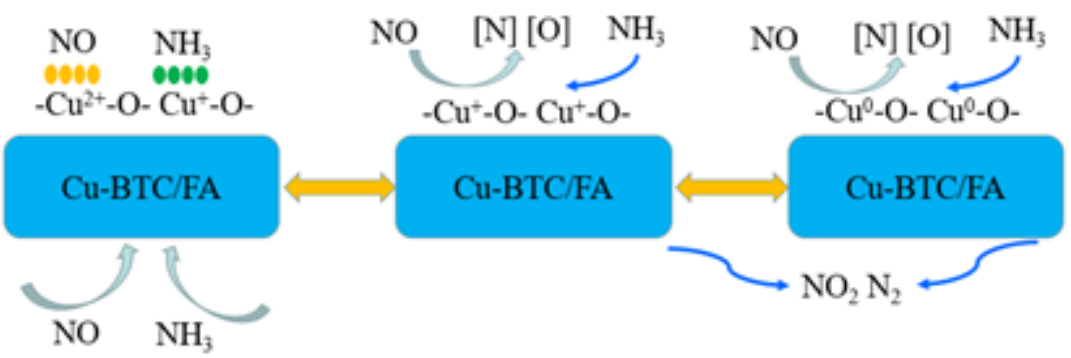

Figure 9

Possible reaction mechanisms for $\mathrm{NO}$ reduction by $\mathrm{NH} 3$

\section{Supplementary Files}


This is a list of supplementary files associated with this preprint. Click to download.

- GraphicalAbstract.pdf 